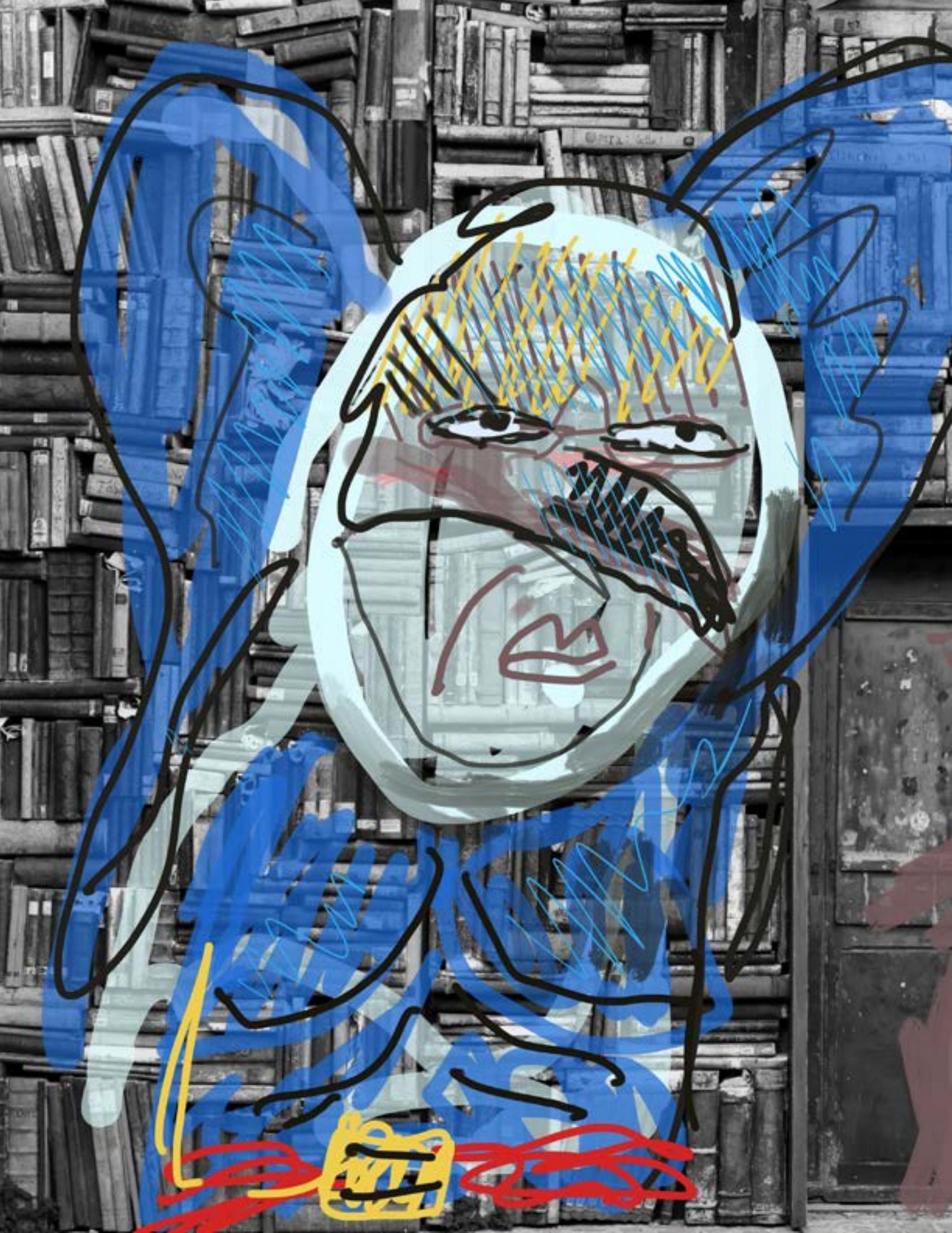




\section{BIRDMAN: LA INESPERADA VIRTUD DE LA IGNORANCIA. LA PUESTA EN CÁMARA COMO OBJETO DEESTUDIO}

\section{BIRDMAN: THE UNEXPECTED VIRTUE OF IGNORANCE. PUTTING ON CAMERA AS AN OBJECT OF STUDY}

\section{Sebastián Guarneros Domínguez}

doi.org/10.37646/huella.v14i14.15

\section{Notas sobre el autor:}

Egresado de la licenciatura en Ciencias de la Comunicación por la Universidad La Salle Pachuca.

Es director, escritor, productor y fotógrafo de cine independiente y contenido audiovisual.

Esta investigación fue financiada con recursos del autor. El autor no tiene ningún conflicto de interés al haber hecho esta investigación.

Remita cualquier duda sobre este artículo al siguiente correo electrónico: sebas_blue_00@hotmail.com

Recibido: 9/07/2020

Corregido: 28/09/2020

Aceptado:1/10/2020 


\section{Resumen}

Es bien sabido que la cinematográfica reúne características principales de otras artes, sin embargo, la puesta en cámara es uno de aspectos que le da esencia al cine, por lo que, cada acción que realiza la cámara será a favor de la historia y su semiótica. Birdman: La inesperada virtud de la ignorancia (2014) es el quinto filme del director Alejandro González Iñárritu, el cual narra un drama sarcástico con una crítica hacia la industria cinematográfica, dichos aspectos narrativos se ven reflejados en la puesta en cámara, factor que hace de esta película un objeto de estudio interesante para comprender la gran importancia que tiene la cámara con respecto a la historia, por lo tanto, en este artículo de investigación analizaremos tres secuencias importantes dentro del filme y su relación con la trama e historia.

Palabras clave: Puesta en cámara, montaje, diseño de producción, símbolo, plano.

\section{Abstract}

It is well known that filmmaking meets the main characteristics of other arts, however, the setting on camera is one of the aspects that gives cinema its essence, since each action carried out by the camera will be in favor of history and its semiotics. Birdman: The unexpected virtue of ignorance (2014) is the fifth film by director Alejandro González Iñárritu, which narrates a sarcastic drama and with a critique of the film industry, these narrative aspects are reflected in the setting on camera, a factor that makes this film an interesting object of study to understand the great importance of the camera with respect to history, therefore in this research article we will analyze three important sequences within the film and its relation to the plot and history.

Keywords: Camera setting, montage, production design, symbol, shot. 


\section{ANTECEDENTES}

Alejandro González Iñárritu es un prolífico director mexicano de cine que ha demostrado una versatilidad en los medios de comunicación. Inició su carrera en la radiodifusora 96.9 WFM; posteriormente incursionó en la televisión de la mano de Televisa, principalmente, dotando de personalidad a cada canal de esta cadena; después, se perfiló hacia el séptimo arte, colocándose como un joven director con su primer filme Amores perros (2000) que rompió el récord al obtener y ganar diversas nominaciones, una de ella fue en el Festival de Cannes del año 2000 y el Premio Oscar como mejor película extranjera en 2001. Lamentablemente, la situación del país estaba en muy malas condiciones con respecto a la violencia, por lo que G. Iñárritu tuvo que salir del país con apoyo del actor Sean Penn; este cambio radical le permitió abrirse camino en los Estados Unidos con la película 21 gramos (2003), que le generó otro nivel de prestigio y contribuyó a que filmara películas internacionales como $\mathrm{Ba}$ bel (2007), Biutiful (2010), Birdman (2014) y El renacido (2015).

Sus últimas películas lo colocaron en lo más alto de su carrera cinematográfica, puesto que fue galardonado como mejor director y mejor película por Birdman (2014) en los premios Oscar; al año siguiente, volvió a ganar el premio Oscar en la categoría de mejor director por $E l$ Renacido (2015); sin embargo, de toda su fil- mografía analizaremos su obra más polémica, Birdman, específicamente su puesta en cámara con relación a la trama y el contexto social de las grandes producciones hollywoodenses, en las que también asoma un sentido paródico.

\section{INTRODUCCIÓN}

Birdman: la inesperada virtud de la ignorancia (2014) es una historia que narra la vida de Riggan Thomson, un actor que fue olvidado por el medio, desde su última secuela de la saga Birdman; ahora busca reencontrarse con su lado artístico mediante la adaptación de una obra de teatro, dicho reto se desenvolverá a la par de sus conflictos personales, específicamente con su ego, el cual se ve representado de manera visual por el personaje de Birdman, este le reprochará sus actitudes y juzgará cada decisión que tome a favor del arte y no hacia la industria o mercadotecnia. Por otro lado, el ámbito familiar del protagonista no es nada favorable y su única solución es no quebrantarlo más.

Dichos círculos, el social, el laboral, familiar e íntimo, pertenecen al cuadrante de complejidad que todo personaje debe tener, puesto que el protagonista tomará una serie de decisiones para alcanzar su objetivo, pero cada cuadrante se verá modificado por otra acción que produzca nuestro protagonista; esta importante regla es mencionada por el aclamado escritor Robert Mckee:

\footnotetext{
${ }^{1}$ A partir del estreno de su quinta película, Birdman, el director modificó su nombre, llamándose, a partir de ahora, Alejandro G. Iñárritu, por lo que omitió su primer apellido debido a motivos de migración, papeleos y pronunciación de acuerdo con una entrevista de Alex Montiel (EstoEs COMBO, 2014).
} 
Hay una cosa muy importante que debes recordar y tener en cuenta al escribir: el protagonista de tu historia debe tener un objetivo, ya que todos los eventos que le sucedan influirán en las formas que elija para lograr este objetivo. Un evento debe estar presente en cada escena de su guion; no escribas escenas adicionales para contar una biografía de tu personaje, porque aburrirá al público. Debe aprender el protagonista de los eventos en los que participa (Mckee, Youtube, 2012).

Durante esta travesía con Riggan Thomson, percibiremos una elegante y directa crítica al medio cinematográfico de Hollywood, con el manejo de los diálogos y tramas, pero particularmente con la puesta en cámara, ya que la película maneja un lenguaje cinematográfico excepcional, de aquí parte este análisis.

La puesta en cámara de Birdman (2014) es una técnica visual también conocida como "plano secuencia", que fue innovada por Alejandro González Iñárritu, director de esta película, sin embargo, este truco visual ya había sido usado desde hace mucho tiempo atrás. No obstante, es importante fragmentar esta puesta en cámara para saber cómo se relacionan todos los movimientos de cámara posibles, cómo el director también logra mantener la continuidad de la narración con saltos temporales sin cortes en un aparente y único plano secuencia en todo el largometraje, acción que también está vinculada con la función narrativa que tiene la cámara.

Otro factor interesante son los tecnicismos para conseguir un único plano (aparentemente) en todo movimiento de cámara, ya sea con tripié, grúa o con cámara en mano; como también la cámara, que cumple con las funciones necesarias de un cine de autor ${ }^{2}$, pero con los grandes artificios de una película de gran manufactura que realiza la industria, teniendo como resultado lo que se conoce como "cortes fantasma", los cuales provienen de herramientas narrativas muy antiguas y ya usadas desde la época del cine en blanco y negro ${ }^{3}$.

Por último, se analizará los artificios técnicos de la puesta en cámara con relación a la semiótica y al lenguaje cinematográfico, ya que, este filme lleva acabo la regla más importante del cine, narrar mediante lo visual, por lo tanto, daremos inicio al análisis de las escenas más importantes y con más carga semiótica con respecto a la fotografía y puesta en cámara.

${ }^{2}$ El cine de autor es un paradigma cinematográfico que se sale de los conceptos industriales y comerciales, generando un modelo más personal e innovador; regularmente, directores como Stanley Kubrick, Alfred Hitchcock, Alfonso Cuarón, etc., se ocupan de diversas disciplinas como la creación del guion o la financiación del filme; otra característica es que mantienen cierta independencia con la industria cinematográfica. (McKee, 2013)

${ }^{3}$ El plano secuencia es una técnica narrativa y de puesta en cámara que consiste en la realización de una toma sin cortes y de larga duración, también permite confabular diferentes tamaños y movimientos de planos; por estas características, se convierte en una técnica compleja. (Zoom f7, 2020) 


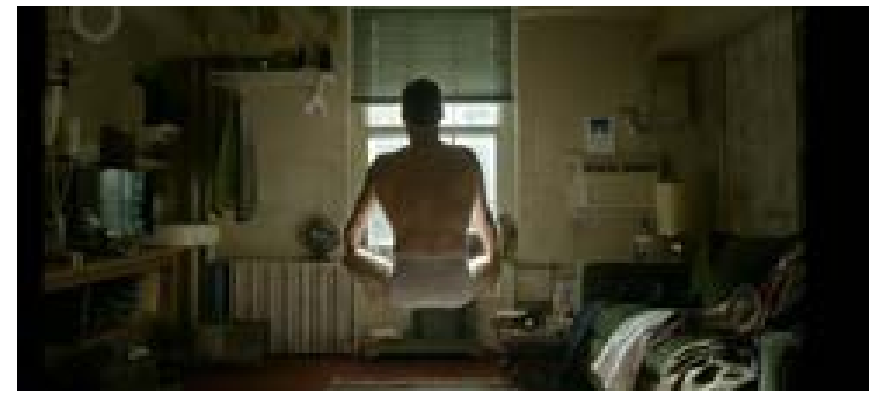

El primer cuadro de la película (Imagen 1) nos muestra las reglas de la misma, al protagonista, su entorno, y su ideología, es un inicio perfecto por el buen uso del círculo de dardos ${ }^{4}$; posteriormente aparece el diálogo, como segundo término, ya que el primero fue el aspecto visual, y nos muestra al segundo personaje que funge como un antagonista de Riggan Thomson, esto se refleja con sus primeras líneas que son insultantes, sin embargo, todavía no sabemos quién o de dónde proviene dicha voz, esta incógnita se resuelve por la puesta en cámara:

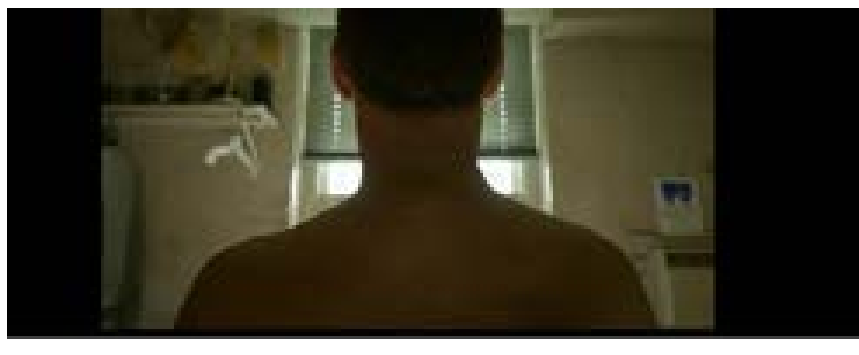

La cámara realiza un Dolly In desde que comienza a hablar la voz y se detiene dejando la cabeza y torso del protagonista en toda la toma (Imagen 2), esto es un indicador del origen de la voz, en otras palabras, se encuentra en la mente del protagonista, no obstante, esto se confirmará en segundos.
Imagen 1.

Primera escena de Birdman. (Iñárritu, 2014)
Imagen 2.

Dolly In a Riggan.

(Iñárritu, 2014)

${ }^{4}$ El círculo de dardos es un truco narrativo que se implementa antes de escribir el guion; se coloca al protagonista en el centro, posteriormente cada círculo que rodeará al personaje principal será una descripción del contexto social, de la ficción como magia, fantasías, ilusiones, monstruos, realismo, etc. Todo tipo de características que ayuden a establecer una coherencia narrativa. El círculo de dardos es un truco que proporcionó Guillermo del Toro en su clase maestra en el Festival de Guadalajara en 2017. (FICM, 2017) 


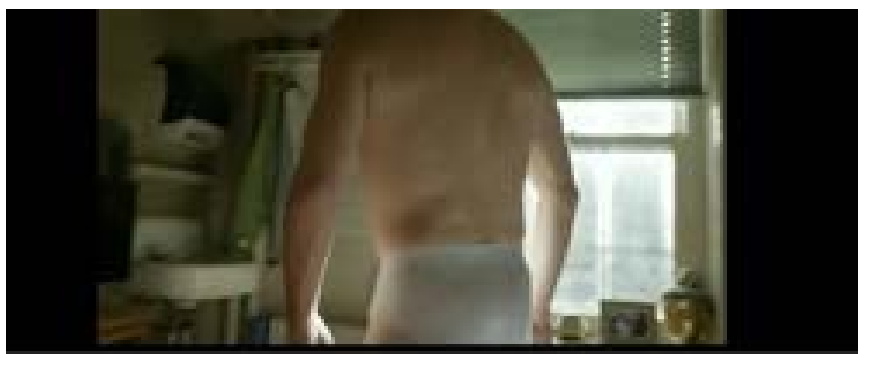

La cámara realiza un paneo izquierdo, demostrando que el protagonista retoma su realidad (Imagen 3); otro factor que nos indica esto es el sonido, la interrupción de los mensajes de la computadora. La película ya nos estableció sus reglas, habrá un juego entre la realidad y la ilusión. La toma avanza y notamos el primer ámbito familiar que tiene nuestro personaje principal.

Riggan Thomson enciende la computadora y tiene una conversación con su hija (Imagen 4); tras un par de diálogos sabemos que es su hija y que trabaja para él, también se destaca la relación que tiene con ella, la cual es muy mala y se basa en el desinterés mutuo.

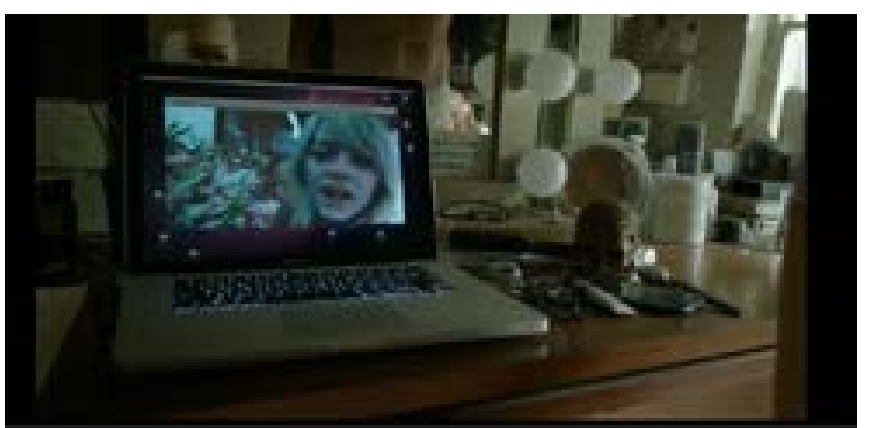

Imagen 4.

Videollamada

con Sam Thomson.

(Iñárritu, 2014) 


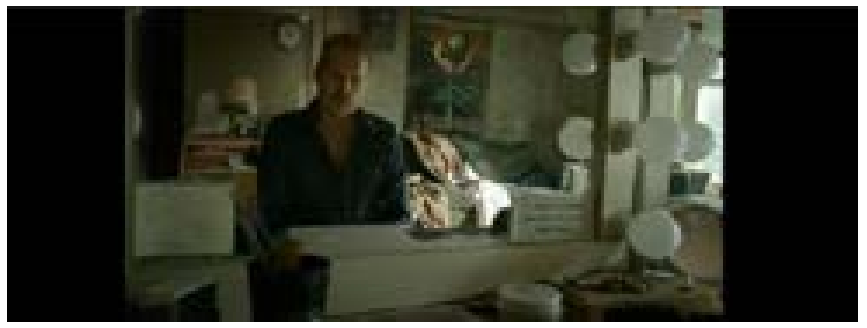

Imagen 5 .

Tilt Up.

Al terminar la conversación, Riggan cierra la computadora mientras que la cámara hace un ligero Tilt Up (Imagen 5), y nos muestra por primera vez el rostro del protagonista, pero también el rostro de la voz misteriosa, es en este momento que nos confirma el origen y aspecto de dicha voz (Imagen 6); todas estas características son narradas de manera visual.

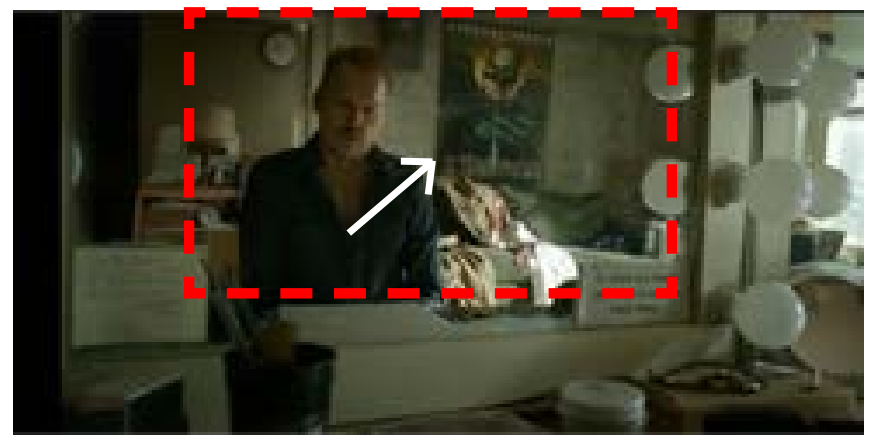

Imagen 6.

Riggan Thomson y Birdman. (Iñárritu, 2014)

La narrativa visual de esta película conlleva varios elementos narrativos y esta toma lo representa; coloca a Riggan Thomson y a Birdman juntos, pero no de manera directa, sino desde un reflejo en el cual los dos se encuentran atrapados; otra característica es el poder que tiene Birdman sobre Riggan, esto se muestra por el cuadro de Birdman que está en una posición más elevada que Thomson, sin embargo, se encuentra por detrás de él, haciendo énfasis en su sombra, ego o esa presencia que siempre estará detrás de él, no importa dónde o cuando, siempre estarán unidos.

Posteriormente, la cámara realiza un paneo derecho hacia el rostro de Riggan Thomson (Imagen 7), el lenguaje cinematográfico toma 
presencia nuevamente, cuando nos indica que nuestro protagonista retoma su realidad, esto lo demuestra a través de dos símbolos, el sonoro con la llamada de su asistente y el visual con la alarma.

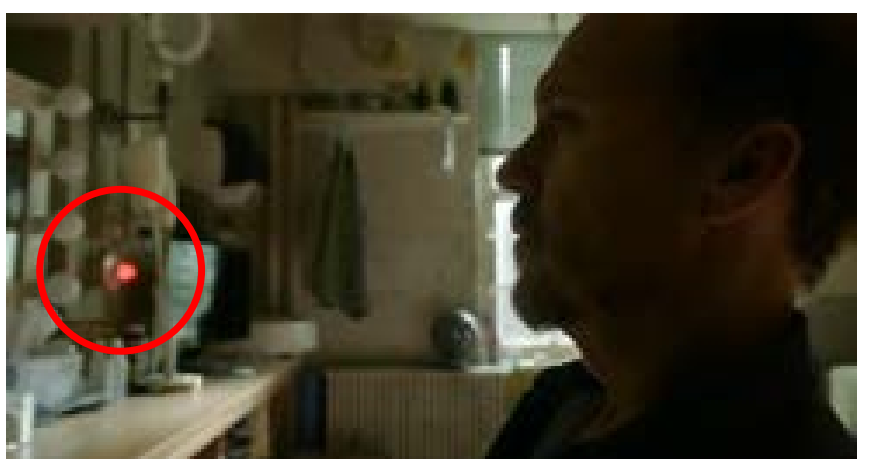

Después, observamos a nuestro protagonista salir del camerino y es en este momento que el director Alejandro González Iñárritu sugiere dos herramientas principales, el plano secuencia como herramienta narrativa y el simbolismo de dicha técnica: la cámara hace un recorrido junto con el protagonista y nos refleja el contexto físico, todo se está llevando a cabo en un teatro; como sabemos, una de las características del teatro es la actuación en vivo, no existen los cortes como en el cine, sin embargo, en este filme se ocupará el plano secuencia para igualar esa característica del teatro.

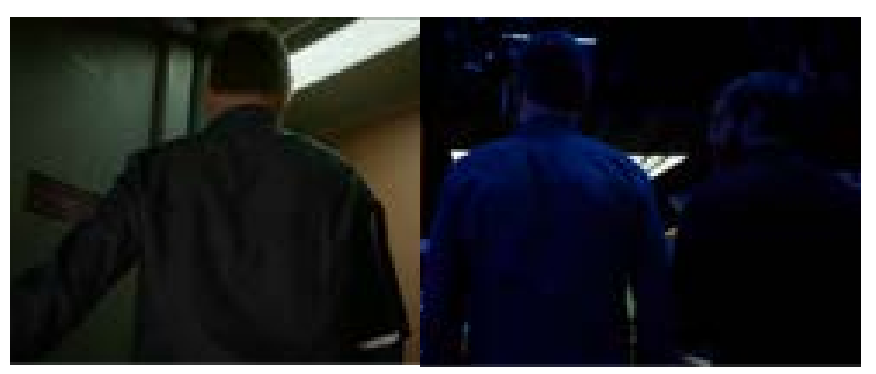

Imagen 7.

Paneo derecho

(Iñárritu, 2014)
Imagen 8.

Conversación entre Riggan

y su abogado/representante. (Iñárritu, 2014) 
Finalmente, la secuencia nos sigue narrando el contexto laboral de Riggan Thomson a través de una conversación que tiene con su abogado y representante (Imagen 8), personaje que es interpretado por el actor cómico Zach Galifianakis; dichos diálogos explican una incomodidad que tiene nuestro protagonista, al no encontrar a un actor que lo satisfaga.

La puesta en cámara de manera estratégica no muestra a los demás personajes (Imagen 9), como también más elementos psicológicos del personaje principal, su perfeccionismo, la pasión que le tiene a la obra de teatro, puesto que Riggan entra a escena como si nada, sabiendo sus diálogos y la temporalidad de la historia.

Vista panorámica de los personajes de la obra de Riggan. (Iñárritu, 2014)

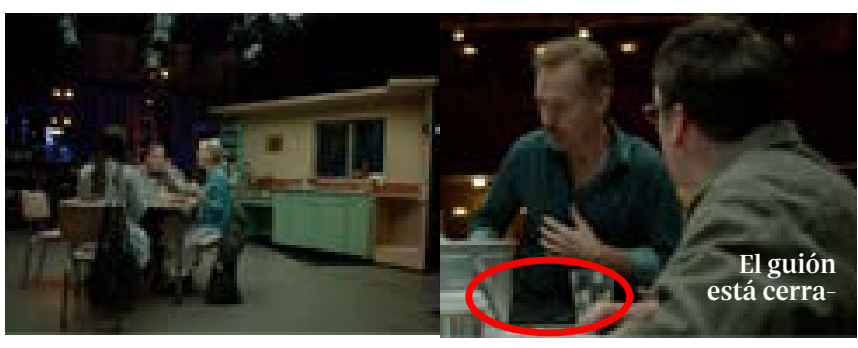

Imagen 10. Desagrado de Riggan.

(Iñárritu, 2014)

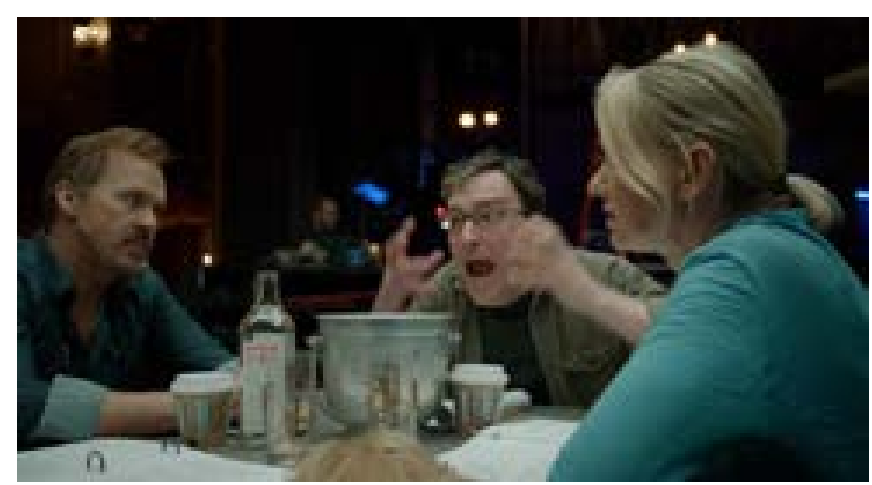

Otro aspecto que nos muestra la cámara es la frustración y enojo que tiene Riggan al ver la actuación de su compañero (Imagen 10). Es en este momento que termina la secuencia, de manera narrativa porque jamás habrá un corte. En cuatro minutos Alejandro González Iñarritu desarrolla la psicología del personaje, su ámbito familiar, el laboral y la social, todos estos aspectos representándolos de manera visual y ocupando el diálogo como refuerzo en segundo término. 


\section{Secuencia II: \\ Birdman rompe la cuarta pared - La crítica y la verdad oculta}

Toda película que fue escrita meticulosamente tiende a darnos dos conflictos, uno general, que pareciera que es el núcleo de toda la historia y que conlleva gran relevancia; y otro que se oculta en el inconsciente de nuestro personaje principal y se va descubriendo a través de la trama, este concepto lo explica Robert Mckee en su clase magistral en la Universidad de Bogotá Jorge Tadeo Lozano, cuando habla del antagonista y del conflicto:

\section{Cuando usted aborda una historia, una de las pregun- tas que tiene que responder es ¿qué nivel o niveles de conflicto voy a utilizar yo para contar la historia? Y cuando se corrige, se vuelve a leer, o se cambia la forma... Usted quiere escribir una historia de amor y usted descubre que el conflicto real es interior, estas personas pueden encontrar el amor si no fueran tan neuróticas, tan fregadas; la historia de amor solo es un contexto y la historia real es la lucha interior (Mckee, Youtube, 2012).}

La película nos coloca como conflicto general (contexto de la película, como lo explica McKee) la realización accidentada de la obra de Riggan, sin embargo, la secuencia que analizaremos nos revela el conflicto verdadero de nuestro protagonista.

La secuencia inicia con un plano en contrapicada, mostrándonos un inmenso edificio y paralelamente aparecen tres pájaros, indicándonos la superioridad que mantiene Birdman sobre Riggan, esto se refleja con el siguiente movimiento de cámara, un plano en picada mostrándonos a Riggan dormido en una bolsa de basura y con un aspecto físico deteriorado (Imagen 11).

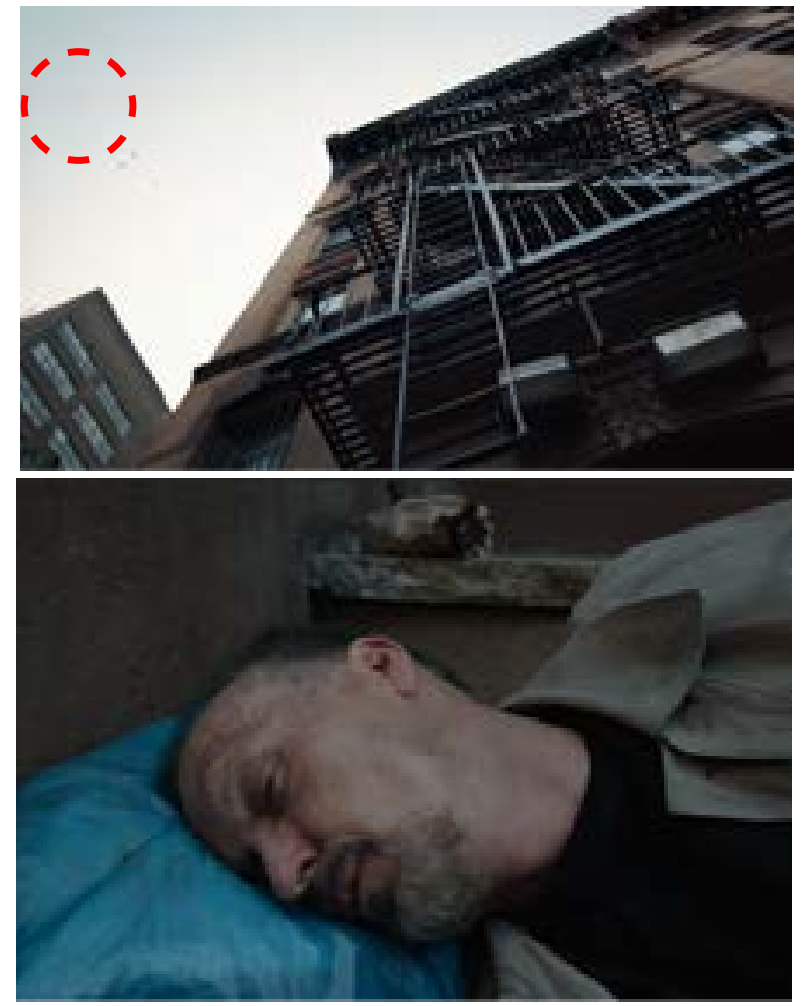

Imagen 11. Contrapicada y Riggan en el basurero. (Iñárritu, 2014) 


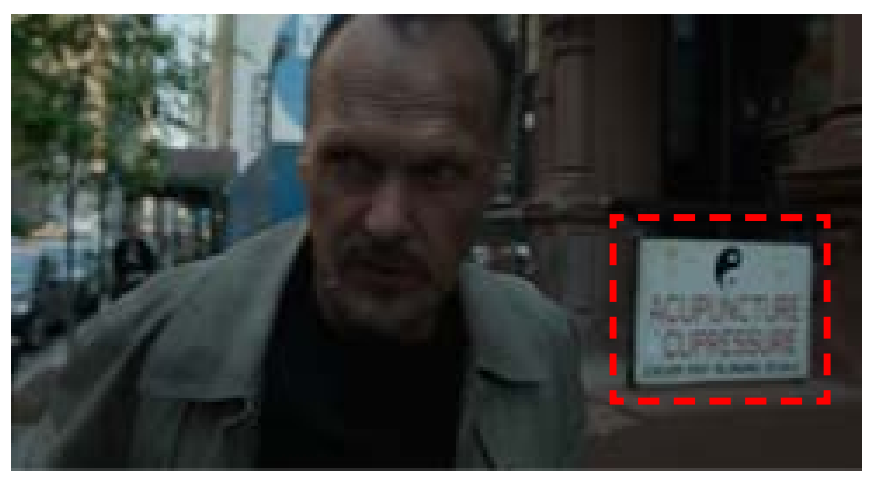

Imagen 12.

Fuerzas opuestas. (Iñárritu, 2014)

Es en este cuadro cuando Birdman comienza a imponerse, sus diálogos son más duros y directos, de igual manera dicha imponencia se refleja en el diseño de producción ${ }^{5}$, con el letrero que refleja el yin y yang, símbolo proveniente del taoísmo, representando dos fuerzas opuestas, otra característica que tiene el letrero son las dos palabras, "acupuntura» $\mathrm{y}$ «cupresión», curiosamente la segunda palabra está mal escrita, debería ser acupresión, al investigar sus significados, son técnicas medicinales chinas, la única diferencia es que en una se ocupan agujas y la otra los dedos, se trata nuevamente de términos contrarios. 

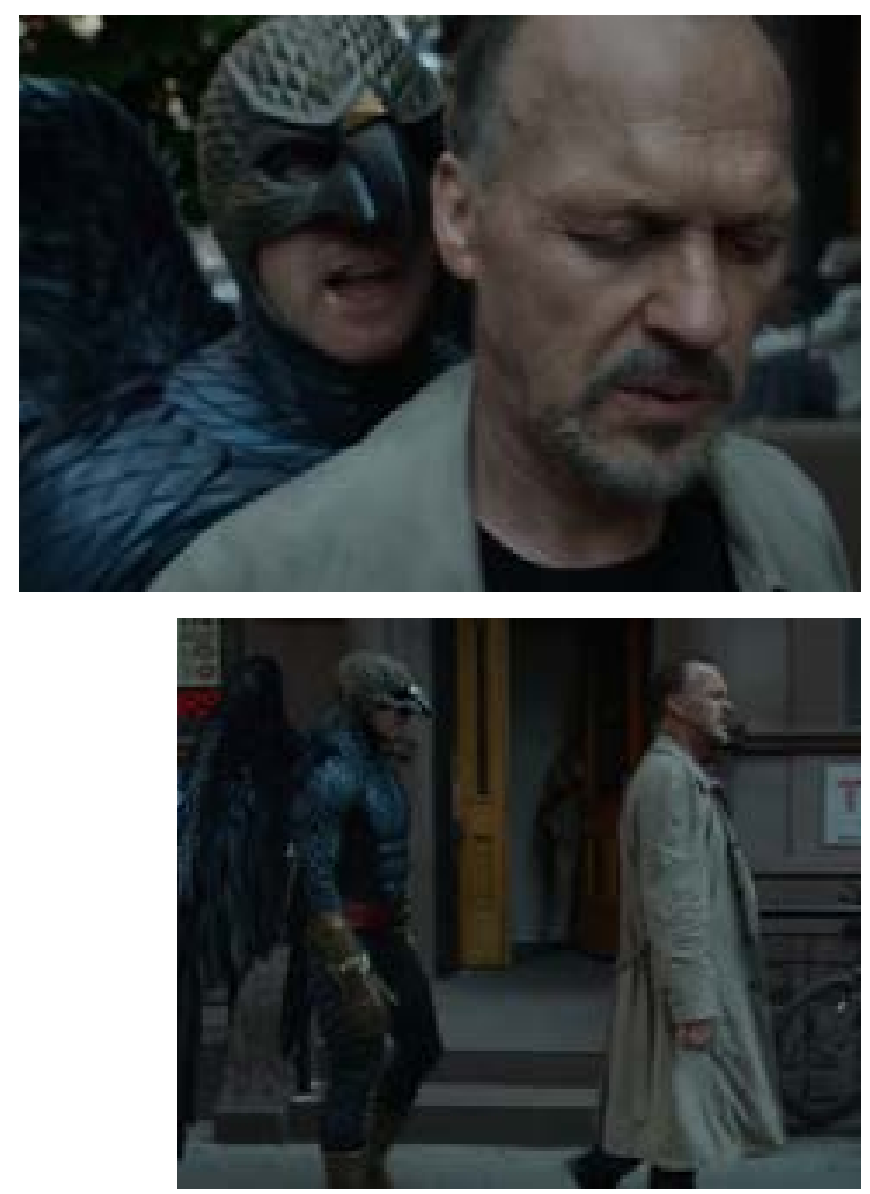

Imagen 13.

Primera aparición visual de Birdman.

(Iñárritu, 2014)

Segundos después Birdman hace su primera aparición visual (Imagen 13); la puesta en cámara nos deja en claro la unión paralela de Birdman y Riggan, pero esta vez lo hace de una manera más cínica hasta con los diálogos, son una crítica directa a la industrialización de la cinematografía, expresando que el arte, la innovación, la originalidad de un autor, son aspectos aburridos y olvidables que generan poco dinero, a comparación de desarrollar un producto para las masas que se convierte en fenómeno y en diversos subproductos de compra.

${ }^{5}$ El diseño de producción es el departamento encargado de elaborar todos los escenarios necesarios de la película. (McKee, 2013) 
Diferentes elementos visuales y narrativos hacen de esta escena una gran ejecución estética, porque va ascendiendo cada vez más, volviéndose cínica al punto de romper la cuarta pared y hablarle al espectador (Imagen 14).
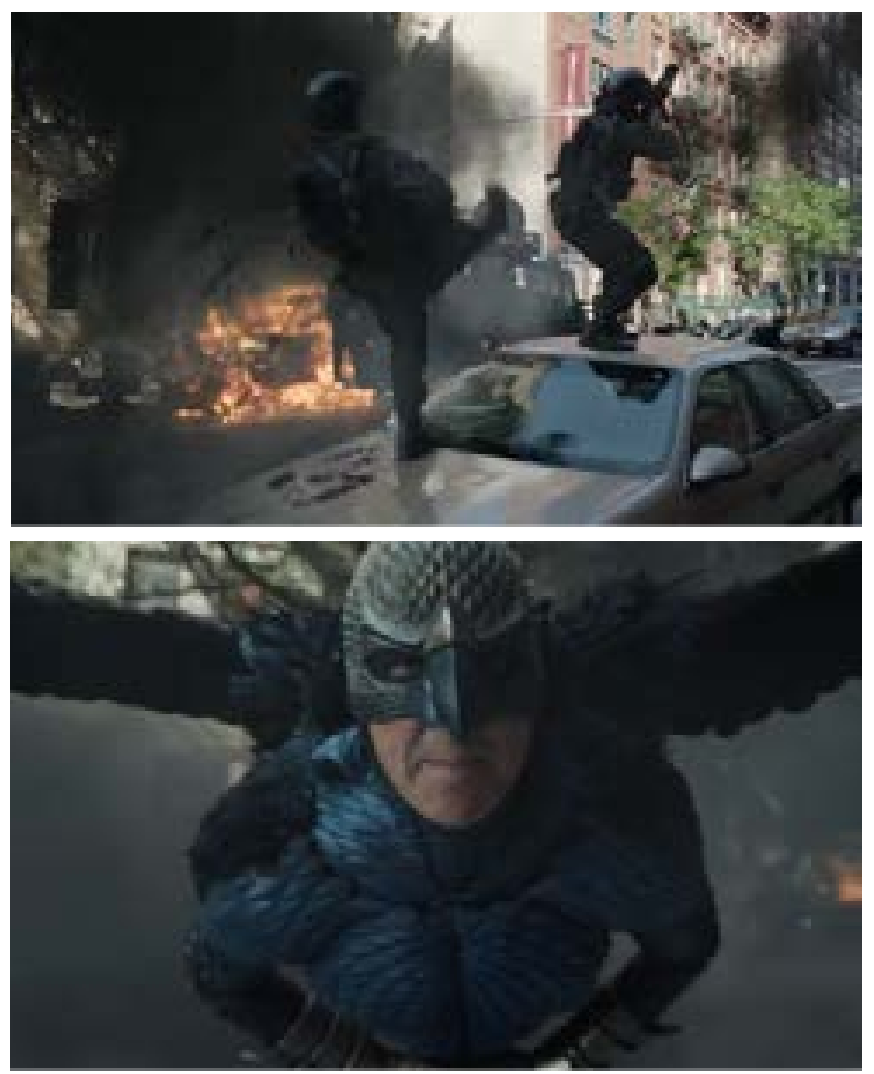

Imagen 14.

Ruptura de la cuarta pared.

(Iñárritu, 2014)
Hago énfasis en el término cínico, porque la mayoría de las películas de superhéroes, de acción, ciencia ficción, terror, etc., comenten el error de ser excesivamente explicativas, agregándole mayor importancia al montaje espectacular y la popularidad de los actores, dejando al olvido el guion. Esta secuencia pone en juego la postura de nuestro protagonista, ya que nos muestran su rostro extasiado por todo lo que Birdman le mencionó y la fantasía continúa cuando Riggan se eleva (Imagen 15).

El vuelo tiene un significado interesante en el filme, puesto que se ocupa como un logro, alcanzar una expectativa, como también estar en el interés del publico. El vuelo tendrá más relevancia en la siguiente secuencia del análisis.
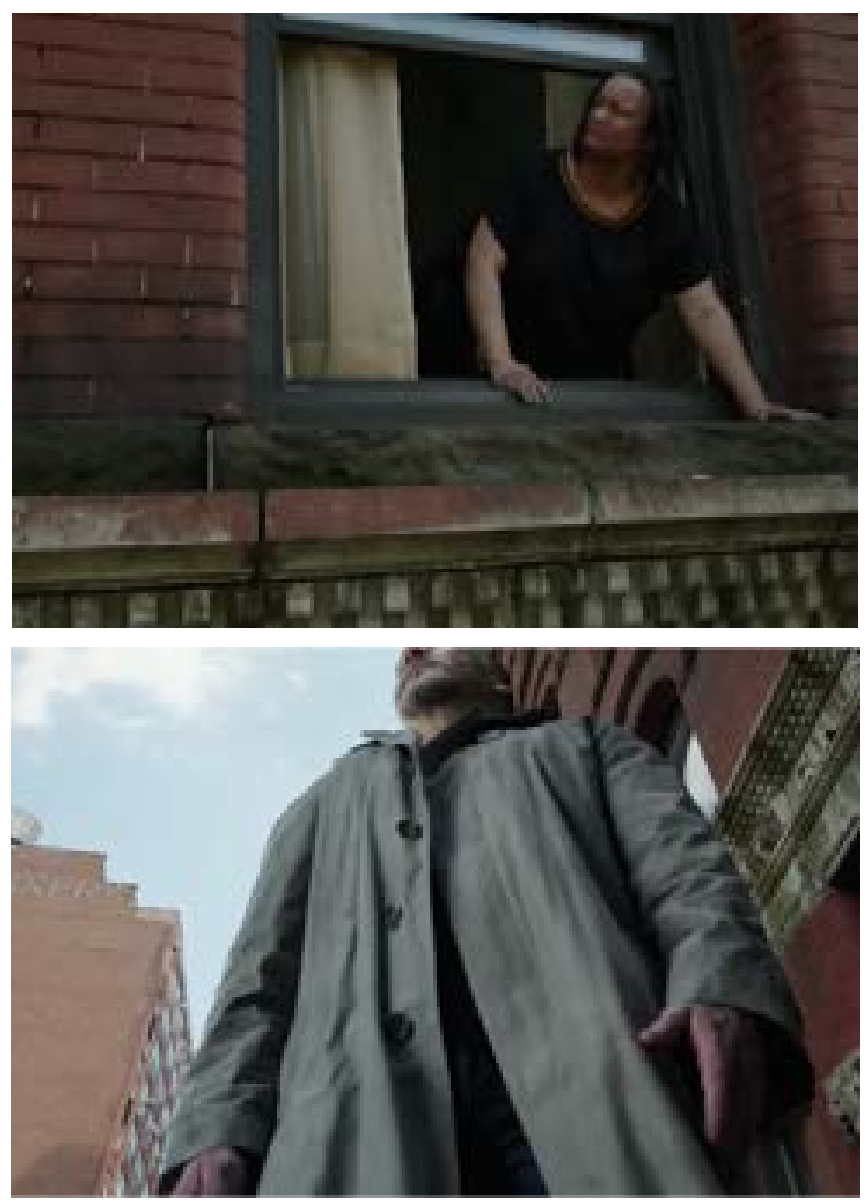

Imagen 15.

Vuelo de Riggan.

(Iñárritu, 2014) 
Podría verse esta secuencia como un montaje bastante exagerado, sin embargo, el argumento que sugiere González Iñárritu es humano y entendible, un ejemplo claro es el actor Michael Keaton que interpreta a Riggan Thomson, se trata de un actor completamente olvidado, el público solo lo recordaba por Batman de 1989, película dirigida por Tim Burton, años después dicho actor regresa con un cenital amplio por Birdman en 2014, colocándose nuevamentecomo un actor de prestigio, tres años después, el actor toma el papel de El Buitre, antagonista de la película, El hombre araña regresa a casa (2017).

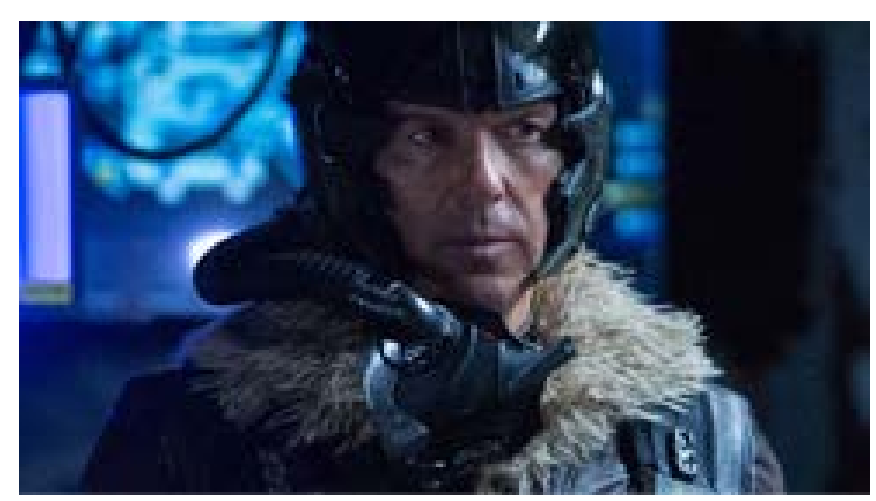

Spider-Man: de regreso a casa, (Watts, 2017)

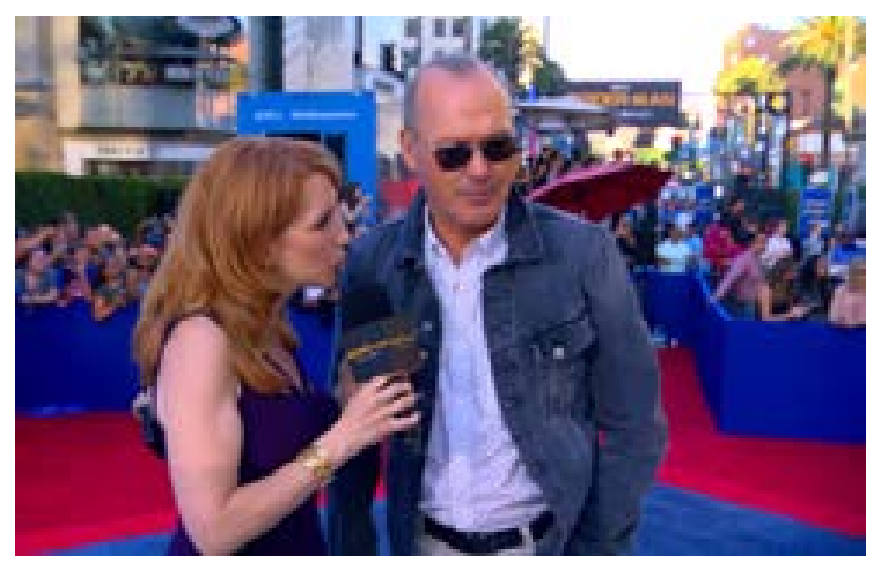

Alfombra roja de Spider-Man: de regreso a casa. 


\section{Análisis de escenas}

\section{Secuencia III: La inesperada virtud de la ignorancia de Riggan Thomson}

Concluir el tercer acto es un reto narrativo, puesto que se debe concretar o cambiar el rumbo con el cual se comenzó; mostrar los logros conseguidos puede ser una decisión propia del director, pero estrictamente debe notarse un cambio, ya que, es una validez del viaje que vivió el personaje protagónico; en el caso de Birdman, culmina con los aspectos a los que se les dio importancia desde el principio, ya que, resuelve los dos conflictos primordiales unificándolos en un mismo hecho.

El inicio de la culminación del filme es cuando Riggan decide agregarle balas de verdad a su pistola para que posteriormente se dispare en público (Imagen 17); este acto intrigó a los espectadores, generando un silencio largo e incómodo, esto se ve reflejando con el sonido de los aplausos que surge de manera paulatina. Alejandro González Iñárritu unifica la resolución de estos dos conflictos en un mismo hecho y en un mismo lugar, el hospital (Imagen 18).
Es en este momento, donde el director nos explica de dos maneras diferentes los resultados; una en la que se ocupa el diálogo como recurso principal para mostrar el éxito de la obra. Su mánager lo felicita, mostrándole el periódico con el subtítulo que tiene la película (Imagen 19), como también todo el impacto social con la prensa y la crítica; por el otro lado, Riggan Thomson ya es parte del internet, esto se muestra cuando su hija le dice que es tendencia en Twitter (Imagen 20).
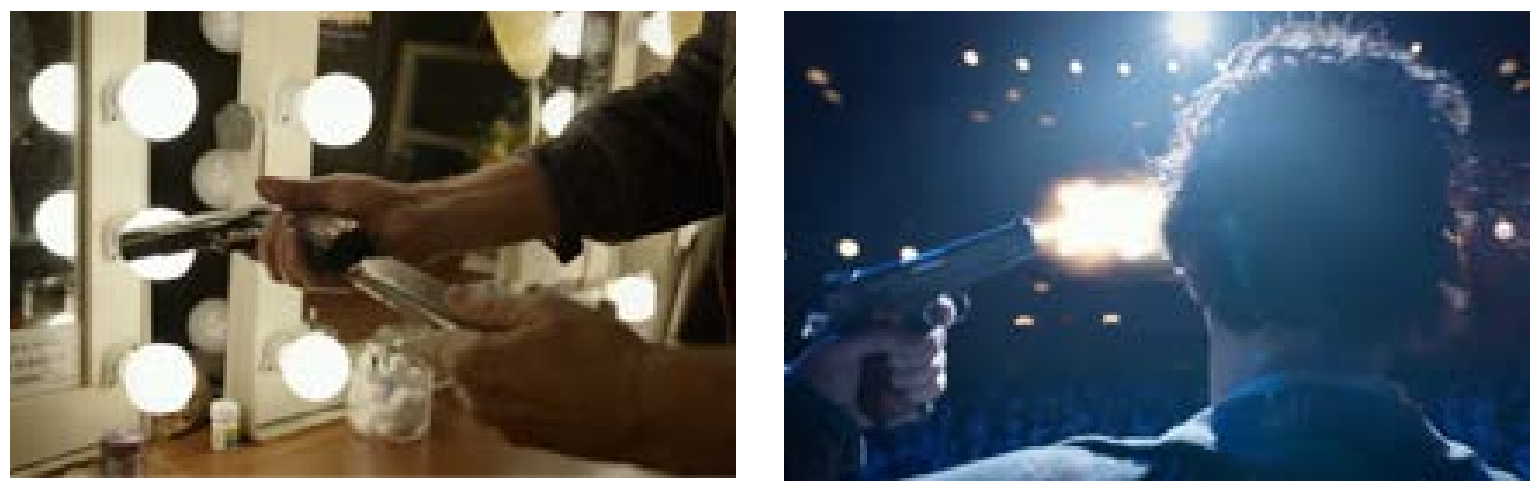

Imagen 17. Acto final de Riggan. (Iñárritu, 2014) 


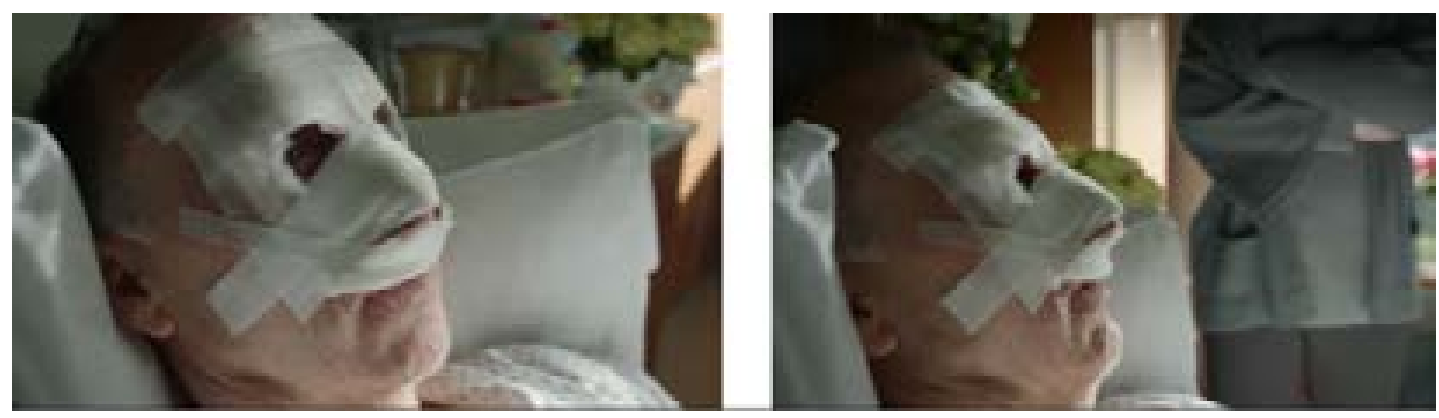

Imagen 18. Riggan en el hospital. (Iñárritu, 2014)

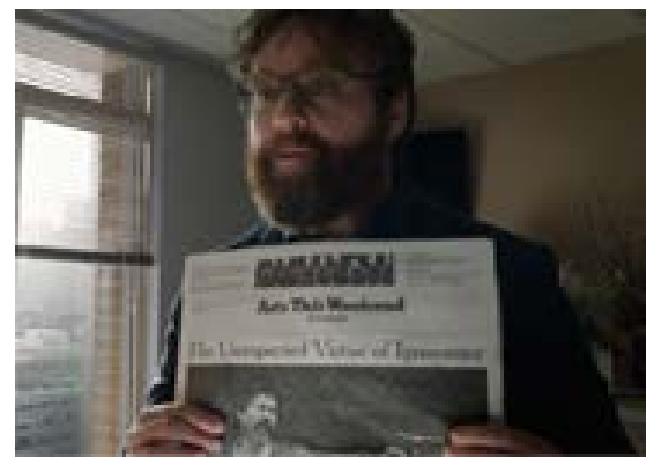

Imagen 19. Buenas noticias. (Iñárritu, 2014)

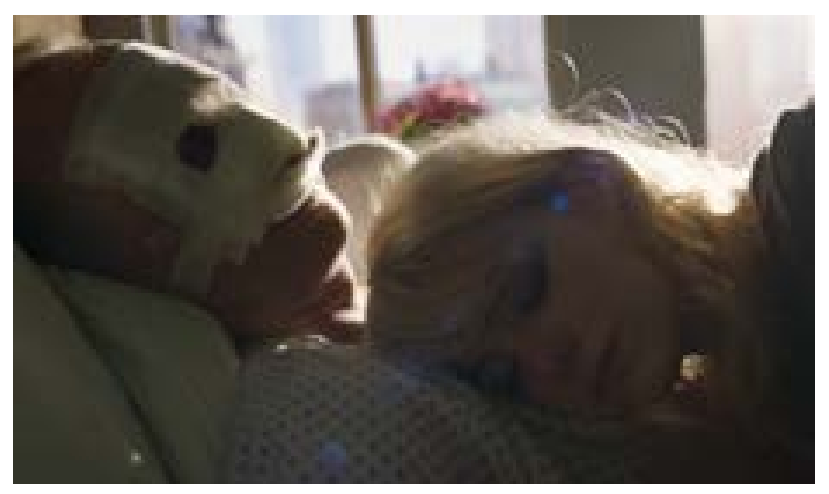

Imagen 20. Padre e hija. (Iñárritu, 2014) 
Posteriormente, todos salen del cuarto para darle espacio y privacidad a Riggan, es en este momento que el director cambia los diálogos por un lenguaje totalmente cinematográfico. Riggan Thomson se levanta, dirigiéndose al baño para observarse en el espejo, posteriormente decide quitarse las vendas del rostro; esto refleja cómo nuestro protagonista se quita su máscara para ver su rostro real (Imagen 21); el símbolo de quitarse las vendas refleja que ya dejó atrás a Birdman para dar paso a un rostro nuevo, a un nuevo él.

Este acto marca la evolución del personaje protagónico y se reafirma con la puesta en cámara, puesto que, la cámara hace un paneo izquierdo mostrándonos nuevamente a los dos personajes encerrados en un espejo, pero esta vez Riggan Thomson se encuentra en una posición superior que el personaje de Birdman, ya que este se encuentra sentado en el escusado y paralelamente escuchamos el sonido de la palanca del baño, indicando con sutileza que todo lo que representa Birdman, como la industrialización del cine, es un producto desechable a diferencia de una creación artística (Imagen 22).

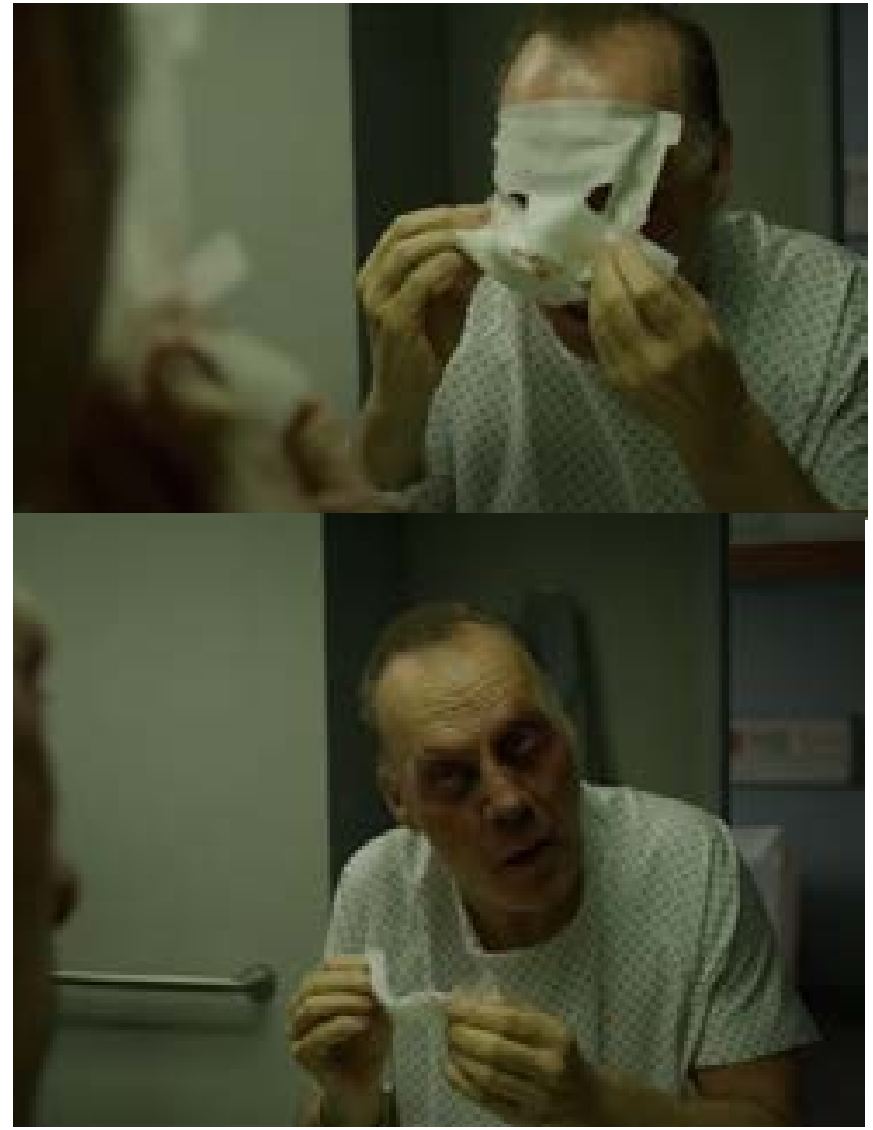

Imagen 21. Quitándose la máscara. (Iñárritu, 2014)

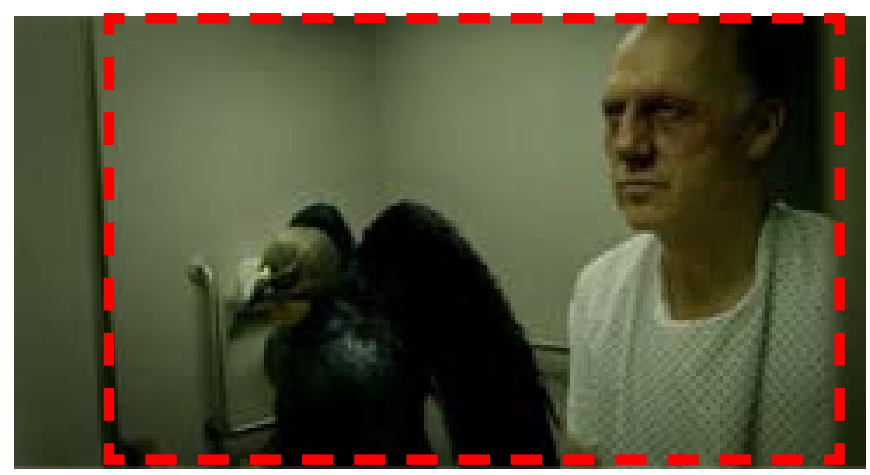

Imagen 22. Productos desechables. (Iñárritu, 2014) 
Posteriormente, Riggan se retira del baño para observar por la ventana del cuarto, apareciendo la inmensidad desde un edificio alto y un grupo de pájaros (Imagen 23), todo esto lo observa estando en un punto alto y ya no desde abajo, es por eso por lo que abre la ventana para realizar su vuelo, el cual todos están mirando, como su hija (Imagen 24); Riggan transcendió como personaje y venció su conflicto personal y se convirtió en un actor reconocido por algo artístico.

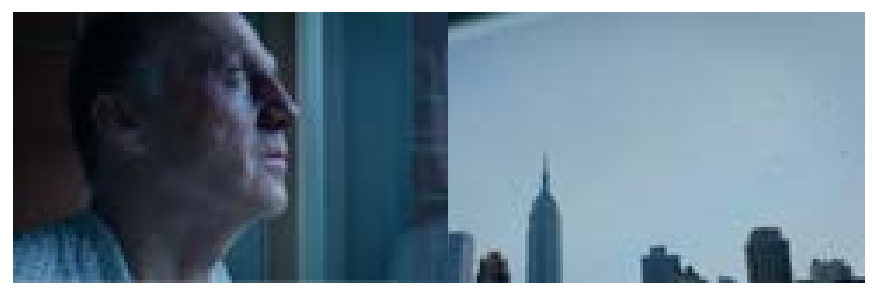

Imagen 23. Vislumbrando el horizonte. (Iñárritu, 2014)

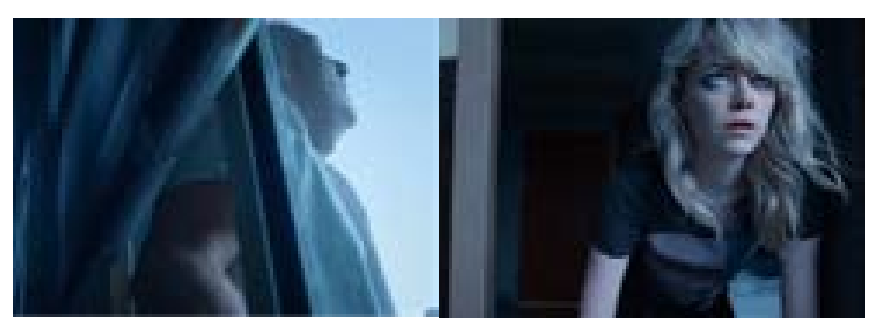

Imagen 24. Secuencia final. (Iñárritu, 2014)

El final de Birdman, deja dos incógnitas: su significado y su nivel de realismo, ¿Riggan voló? o se suicidó? Aparentemente, Alejandro González Iñárritu nos muestra un final interpretativo, sin embargo, si ponemos atención a las reglas del universo de Birdman, podemos interpretar la verdad de este final, ya que cada historia correctamente escrita conlleva una coherencia en su arquitrama, minitrama o antitrama; en otras palabras, sobre sus reglas en el mundo que viven los personajes, este tema lo explica Robert Mckee en su libro El guion:

\section{Aunque las variaciones del diseño de los acontecimien- tos son innumerables, no carecen de limitaciones. Los extremos artísticos crean un triángulo de posibilidades formales que conforman el mapa del universo narra- tivo. Dentro de ese triángulo se encuentran todas las cosmologías de los escritores, sus múltiples visiones de la realidad y de cómo se vive la vida en ellas. Para com- prender qué lugar ocupa nuestra narración dentro de ese universo debemos estudiar las coordenadas de ese mapa (McKee, 2013)}

Utilizando el triángulo que propone Robert Mckee (1997) sobre la arquitrama, minitrama y antitrama, comprendemos el filme desde una perspectiva en cenital y sus reglas del universo que propone Alejandro González Iñárritu.

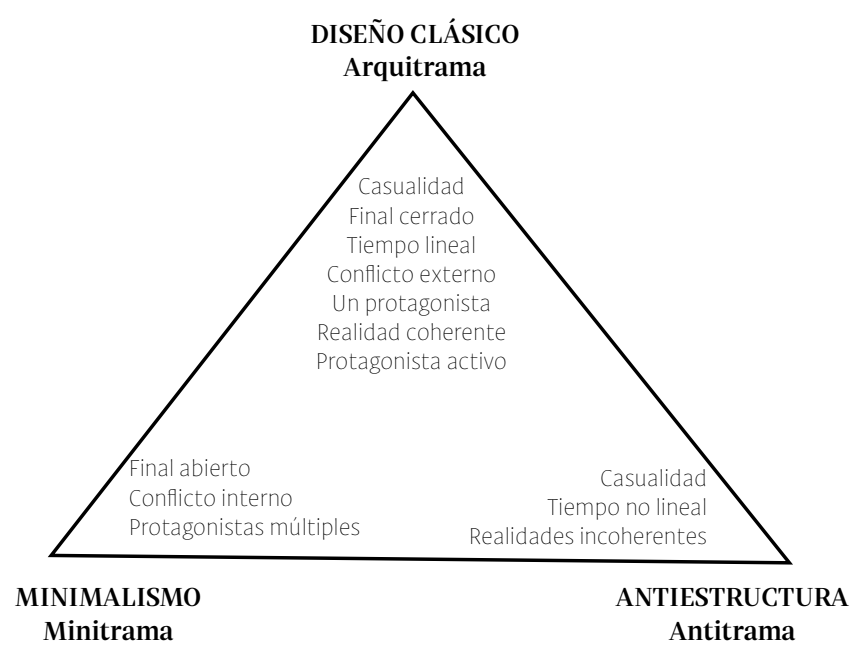


La trama en la que se construye el universo de Riggan Thomson es una minitrama o minimalismo, por las siguientes características: el final es abierto porque deja preguntas, las cuales se pueden responder, pero solo obteniendo un análisis, sin embargo, la escena como tal no lo hace. El conflicto interno que sufre nuestro protagonista es el tema principal de la trama, para Mckee un conflicto interno es:

\section{En la minitrama, por el contrario, el protagonista po- dría tener poderosos conflictos externos con su familia, con la sociedad y con el entorno, aunque se destacan las batallas que se producen dentro de sus propios pen- samientos y sentimientos, conscientes e inconscientes. (2013)}

Como hemos analizado, en Birdman (2014) la verdadera lucha son los deseos de Riggan contra los de Birdman, su alter ego. Posteriormente, se encuentra el término protagonistas múltiples, Mckee lo explica de una forma muy precisa:

Sin embargo, si el escritor divide la película en diversos relatos relativamente pequeños y con un tamaño de trama secundaria, cada uno de ellos con su protagonista independiente, el resultado reducirá al mínimo la dinámica de montaña rusa de la Arquitrama y creará la variación de tramas múltiples de la minitrama (2013).

El montaje de la película es coral, porque intervienen demasiados actores, con tramas muy pequeñas; por ejemplo, tenemos a la hija de Riggan, Sam Thomson, quien trabaja con su padre para mantenerse ocupada y estar fuera de las drogas; por otro lado está el personaje de Lesley, una joven actriz que está obsesionada con la perfección y busca un reconocimiento peramental con talento y con una relevancia dentro del medio en comparación de sus compañeros, sin embargo, sigue estando detrás de Riggan Thomson. En comparación, todos los personajes son muy inseguros de sí mismos, compiten contra sus propios egos, sin embargo, la lucha principal es la de Riggan Thomson contra Birdman.

El protagonista pasivo es un concepto específico con el que cuenta este filme; Robert McKee dice: "Un protagonista pasivo se mostrará externamente inactivo mientras persigue un deseo interior que está en conflicto con otrosaspectos de su propia naturaleza" (2013). Es exactamente la representación de nuestro protagonista; como se había mencionado antes, la realización de la obra es el conflicto general y nunca nos muestran a Riggan solucionándolo, incluso en los primeros minutos vemos como todo cae sobre el mánager, interpretado por Zach Galifianakis, incluso podríamos decir que Riggan huye de su realidad como también de su interioridad, y lo único que lo lleva a conseguir su meta es la desesperación y la impotencia de suicidarse, acto fallido que paradójicamente le otorga el éxito, Riggan Thomson es un personaje pasivo.

Al generar una radiografía de la trama de la película, podemos comprender las reglas del universo que crea Alejandro González Iñárritu y, por ende, el significado del final; los conceptos clave son el conflicto interno y el protagonista pasivo, estos factores propician que la mayor parte del filme sigamos y veamos la perspectiva de Riggan, esto nos lleva a presenciar cuando está fuera o dentro de la realidad. 
Por ejemplo, en un plano nos muestra la telequinesis que tiene Riggan sobre los objetos, pero a los pocos minutos la cámara genera un paneo que rompe repentinamente las ilusiones de nuestro protagonista, evidenciando que su poder sobrenatural solo es una furia contenida que lo lleva a romper y arrojar objetos con sus propias manos (Imagen 25).

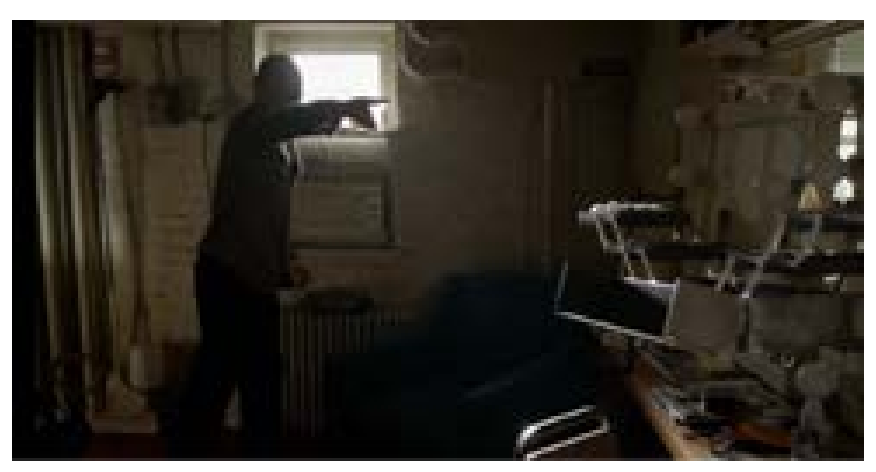

Imagen 25. Telequinesia (Iñárritu, 2014)

El director ocupa una fórmula continua para interrumpir las ilusiones de Riggan, ocupando la perspectiva de un tercero, en la escena del cuarto la cámara panea hacia la derecha para captar la reacción del mánager, posteriormente la toma regresa a Riggan, pero esta vez rompiendo un periódico con sus propias manos (Imagen 26).

Nuevamente volvemos a ver ese contraste entre la ilusión y la realidad, cuando Riggan vuela por toda la ciudad (Imagen 27); este regresa al teatro descendiendo poco a poco, sin embargo, una vez que el personaje entra, la cámara opta por un paneo izquierdo, revelando que Riggan salió de un taxi sin pagar (Imagen 28).
Sin embargo, el director ocupa las ilusiones del personaje protagónico para usarlas como metáforas visuales; el vuelo representa su deseo por tener la atención del público pero, como todo vuelo, necesita tirarse con un acto de fe, ya que puede tener la posibilidad de caer al suelo o ascender sobre él. Es aquí cuando se presenta el segundo vuelo, culminando con la película, el arco narrativo de nuestro personaje principal y contestando las incógnitas: ¿Murió? O ¿Vivió?

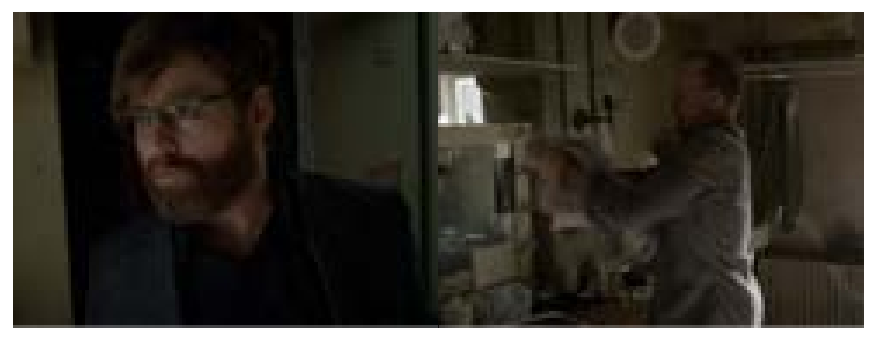

Imagen 26. Perspectiva de un tercero. (Iñárritu, 2014)

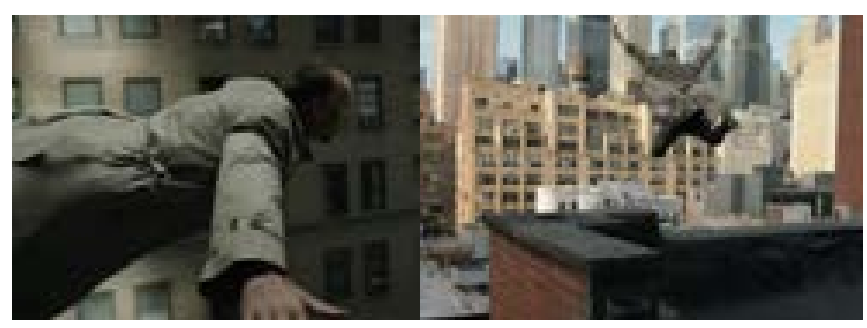

Imagen 27. Riggan vuela por la ciudad. (Iñárritu, 2014)

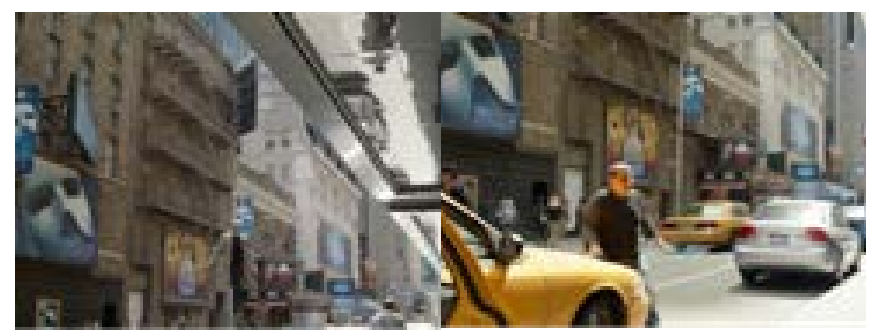

Imagen 28. No voló, iba en taxi. (Iñárritu, 2014) 
La misma fórmula se presenta con respecto a mostrar la ilusión y la realidad, no obstante, el director invierte este proceso, relevándonos que la perspectiva de Riggan es lo que siempre importó en la historia. La realidad se presenta primero, con los reporteros, la interacción de su mánager, hija y esposa y el bullicio mediático, después cuando el personaje se encuentra solo, observando la ventana, la música aparece lentamente y es en ese momento que la ilusión inicia; Riggan no expresa ninguna opinión con respecto a lo externo, a él solo le importa una cosa, el ascenso, volar, ser observado por los otros de la manera que él deseaba; desde el lado artístico, Riggan Thomson trascendió (Imagen 29).

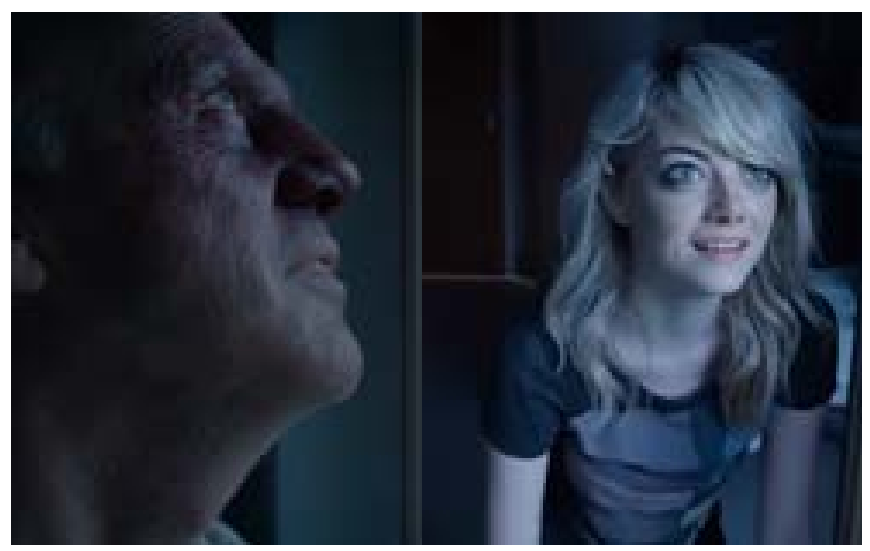

Imagen 29. Trascendió. (Iñárritu, 2014) 


\section{CONCLUSIONES}

Al terminar el análisis de estas tres secuencias que impactan y marcan un cambio en la trama de la película, se concluye que la puesta en cámara maneja un lenguaje audiovisual estratégico y que ningún movimiento es gratuito o que solo busca favorecer una cuestión estética, al contrario, la cámara está al servicio de la historia, por lo cual tiene como finalidad mostrarnos la realidad dentro del universo de Birdman, generando contrastes con lo que se dice y se muestra, como también revelándonos la psicología de los personajes mediante ligeros movimientos de cámara.

Otro punto de análisis fue la interpretación del estilo de trama que maneja este filme, usando el triángulo de tramas que propone Robert Mckee, este aspecto detonó la semiótica que tiene el universo creado por Alejandro González Iñárritu con relación con la puesta en cámara que se maneja; un ejemplo de esto es el significado que tiene el plano secuencia que se desarrolla durante toda la película, con respecto a la obra de teatro que el personaje protagónico debe montar, logrando una metáfora e unión entre el cine y el teatro, en ninguno hay cortes.

Tampoco podemos dejar de lado la crítica que se hace a la industria cinematográfica, y que se muestra con diversas herramientas narrativas como el diálogo, el diseño de producción y el ámbito que estamos estudiando, la fotografia; González Iñárritu logra reunir cada aspecto narrativo de su discurso en algo visual y con una ejecución que nos demuestra su solidez como cineasta y escritor.

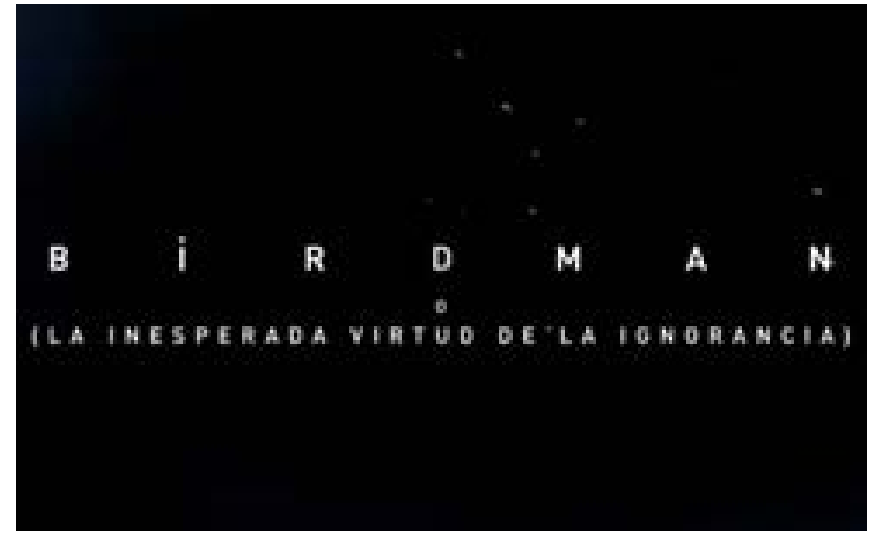

Imagen 30. Fin. (Iñárritu, 2014) 
EstoEs COMBO (2014, octubre 26). Close Up a Iñárritu y Birdman. [Archivo de video]. https://youtu.be/6yBtLFViFJQ

FICM (2017, octubre 28). Primera clase magistral: Guillermo del Toro. [Archivo de video]. https://youtu.be/Mbidtzrg_RU

FilMesLEM (2012, noviembre 10). Robert McKee - El Guion (Story Seminar). [Archivo de video]. https://youtu.be/OBQW8LrdTFY

Iñárritu, A. G. (Director). (2014). Birdman. [Película]. Regency Enterprises; New Regency Pictures; M Productions; Le Grisbi Productions; TSG Entertainment; Worldview Entertainment.

McKee, R. (2013). El guion. Sustancia, estructura, estilo y principios de la escritura de guiones. ALBA.

Zoom f7 (2020, mayo 25). iHagamos cine independiente! (2da versión, el original fue bloqueado). [Archivo de video]. https:// youtu.be/z9kSCfZOy9c 
